\title{
Synthesis of exfoliated PA66 nanocomposites via interfacial polycondensation: effect of layered silicate and silica nanoparticles
}

\author{
HOSSIEN GHARABAGHI, MEHDI RAFIZADEH* and FARAMARZ AFSHAR TAROMI \\ Department of Polymer Engineering and Color Technology, Amirkabir University of Technology, P.O. Box 15875-4413, \\ Tehran 15875, Iran
}

MS received 15 September 2015; accepted 8 February 2016

\begin{abstract}
Nanocomposites of polyamide 66 (PA66) with layered silicate and silica $\left(\mathrm{SiO}_{2}\right)$ nanoparticles were prepared via in situ interfacial polycondensation method. Hexamethylenediamine (HDMA) and adipoyl chloride (AdCl) were reacted in a two-phase media. Montmorillonite (NaMMT) and silica nanoparticles were added to reacting media. Preparation of PA66 and its nanocomposites were studied using Fourier transform infrared spectroscopy. Dispersion of nanoparticles was studied using X-ray diffraction and transmission electron microscopy. The results show that two structures were achieved using two kinds of nanoparticles. Silica nanoparticles were partially exfoliated, while NaMMT nanoparticles were hybrid intercalated-exfoliated in nanocomposite samples. Thermal properties of samples were investigated by differential scanning calorimetry. The results suggest that crystallinity is heterogeneous in the presence of nanoparticles. Kinetic of crystallization was studied by means of Avrami equation, based on the kinetic parameters, spherulites are produced. Results were reported for nanocomposites containing 2 and $4 \%$ of nanoparticles. Avrami equation parameter, $n$, shows that spherulite crystallization occured in the samples. Addition of nanoparticles decreases $\boldsymbol{n}$ first, then $\boldsymbol{n}$ increases with nanoparticle content.
\end{abstract}

Keywords. Polyamide 66; nanocomposite; interfacial polymerization; nanoparticle; crystallization.

\section{Introduction}

Polyamides (PA) are polymers containing amide links. Nylon is a general name for synthetic polyamides. Polyamides were produced by Carothers [1] in 1937 at DuPont Research Center. Polyamides are the most commonly used engineering polymers in textiles, automotive parts, carpet and sportswear due to their superior mechanical properties. Polyamide 66 (PA66) is the most important kind of nylon. PA66 is normally produced via condensation polymerization of aqueous solution of hexamethylene adipamide salt or hexamethylenediamine and adipic acid over long periods at high temperature and pressure [2]. Consequently, produced polymer goes under solid-state polymerization (SSP) in the presence of an inert gas flow to reach high molecular weights. Alternative method of PA66 synthesis is interfacial polycondensation (IPC) of hexamethylenediamine and adipoyl chloride [3]. The main distinguished feature of IPC is its operability at room temperature in a simple lab-scale set-up. Moreover, it is possible to reach high-molecular weight PA66 in IPC. IPC is a heterogeneous reaction consisting of aqueous and organic phases. Polymerization takes place near the interface in the organic phase; hence, this process is normally diffusion-controlled [4]. Hydrochloric acid $(\mathrm{HCl})$, as reaction by-product, is removed to perform reaction in favour of

\footnotetext{
*Author for correspondence (mehdi@aut.ac.ir)
}

polymer production based on the Schotten-Baumann mechanism [4]. Effective variables are reactant concentrations, diamine to acid ratio, rate of polymer removal, stirring speed, etc. [3]. Moreover, it is important to prevent the hydrolysis of acid chloride (adipoyl chloride) to less reactive diacid (adipic acid) in contact with the aqueous phase. Fathizadeh et al [5] prepared polyamide reverse osmosis (RO) membranes by interfacial polymerization of trimesoylchloride (TMC) and m-phenylenediamine (MPD) monomers over a polyethersulfone (PES) support layer. They evaluated the separation performance of the fabricated thin film composite (TFC) membranes by a cross flow flat sheet RO membrane unit. Matthews et al [6] synthesized polyamide films via interfacial polymerization to produce active layers in RO membranes. They used real-time diffuse optical reflectance to monitor the growth dynamics of polyamide. They related polyamide thickness to optical absorption changes. Lee et al [7] made thin film composite membrane via interfacial polymerization of two monomers, 1,3-phenylenediamine and trimesoyl chloride, which is responsible for high salt rejection. They investigated membrane thickness as a function of polymerization time and monomer concentration. Hermans et al [8] presented a simplified method for the synthesis of thin film composite membranes via interfacial polymerization. They carried out the phase inversion step and the impregnation with the amine monomer simultaneously by adding the amine to the coagulation bath before immersing the cast polymer film. 
One approach to improve polymer properties and widen their applications is to make polymer composite with appropriate fillers. In the recent decade, preparing nanocomposites have been attracted a great deal of attention because of enhancement in various properties such as thermal behaviour, mechanical strength and stiffness, compared to neat polymer [9-31]. There are various methods to produce nanocomposites: melt intercalating [9-17], solution mixing [18] and in situ polymerization [9-32], etc. Polymer nanocomposites, involving polyamides, mostly are prepared using melt mixing approach. Liu and $\mathrm{Wu}$ [9] studied crystallization behaviour of polyamide-6 (PA6)/clay nanocomposites. They reported that the addition of clay influenced the nucleation and the growth of PA6 crystallites. PA66/nanoclay nanocomposites have been investigated intensively [10-17]. In some researches, up to $10-20 \%$ of MMT and organo-modified montmorillonite (OMMT) were added to PA6 and PA66, and mixed in a twin screw extruder. Hedicke et al [14] studied crystallization behaviour of injected polyamide/MMT nanocomposites. They found that the thin clay platelets affect the crystal structure of PA6 and the crystallization rate of both types of polyamides. Yang et al [15] prepared PA66/MMT by melt mixing. The crystallization behaviour and crystal structure of matrix were studied. They found that the melting point and crystalinity of the matrix polyamide/MMT nanocomposites prepared PA6/OMMT master-batch are lower than those from PA66/OMMT master-batch. Zou et al [18] gave an overview on preparation, characterization, properties and applications of polymer/silica nanocomposites including various polymers prepared with different methods. Sengupta et al [19] prepared hybrid nanocomposites of PA66 and silica $\left(\mathrm{SiO}_{2}\right)$ through sol-gel technique. They studied microstructure, thermal and mechanical properties of produced samples. Lu et al [20] prepared PA66/silica nanocomposites via mixing in a twin screw. They found 109\% improvement in loss modulus for $1 \mathrm{wt} \% \mathrm{PA} 66 / \mathrm{SiO}_{2}$ nanocomposites compared to neat PA66 at $-40^{\circ} \mathrm{C}$ based on the DMA results. $\mathrm{Xu}$ et al [21] produced PA66/surface-modified nano- $\mathrm{SiO}_{2}$ nanocomposites by melt compounding. They reported that the PA66 chains have chemical bonding with the surface of modifiedsilica nanoparticles, accompanying the formation of the composites network structure. Hence, it was normally observed that nanoparticles play nucleating agent role to increase the rate of crystallization and influence quality of crystal, which improves many of the properties.

Recently, some researches have been published on the production of PA66/MMT nanocomposites using IPC [22-33]. Botelho et al [22] synthesized PA66 using hexamethylenediamine and adipoyl chloride in the presence of carbon fibres to produce composites. One of the main objectives of producing PA66 via IPC is forming membrane for the sake of separation $[23,24]$. Polyamide/carbon nanotube was produced by some researchers [24,25]. Unmodified and organo-modified nanoclay and PA66 nanocomposites have been investigated thoroughly [26-33]. Tarameshlo et al [26] prepared exfoliated PA66/silicate layered nanocomposites using IPC. They studied morphology, thermal stability and crystallization behaviour of the obtained nanocomposites. The results indicated that the OMMT nanoparticles were dispersed homogeneously in the PA66 matrix (nearly exfoliated morphology) and improved thermal stability, crystallization rate and crystallization temperature of PA66. Song et al [27] synthesized PA66/OMMT exfoliated nanocomposites using ammonium salt of the aminocaproic acid solution. Their results indicate that the exfoliated nanocomposites have enhanced thermal stability and flame retardancy compared with neat PA66. Kalkan and Goettler [28-30] in a triplex, published papers on synthesized PA66/MMT nanocomposites via in situ IPC in both stirred and unstirred reactors and sol-gel methods. They studied effect of mixing methodology, reaction conditions, concentration ratio and clay content on polymer molecular weight. They showed that stiffness enhanced. They mentioned that MMT has better thermal stability than OMMT. They studied the effect of various amounts of MMT added to reactive mixture on dispersion of nanoparticles. Moreover, they studied dynamic mechanical analysis (DMA) of samples. In the last paper, Kalkan and Goettler [30] prepared PA66-silica nanocomposites through sol-gel approach. They used nonfunctionalized silica and bonded silica through a functionalized silane. They studied the effects of agitation and water-to-silane molar ratio on the courses of the inorganic and organic reactions and generated nanocomposite morphology. It is concluded that most researchers in the field of PA66 nanocomposites have been concentrated on montmorillonite. However, preparing and comparing properties of PA66/silica nanocomposites could give better insight into their applications.

In the present research, PA66/layered silicate and silica nanocomposites were synthesized via interfacial polymerization. PA66 was synthesized with the reaction of hexamethylenediamine (HDMA) and adipoyl chloride ( $\mathrm{AdCl})$ in a two phase media. Although results of previous researches show the effect of various parameters such as monomer ratio, nanoparticle modification and etc. But still it is worth to study the effect of nanofiller shape on product structure and properties. Appropriate nanoparticles were added to the media to prepare nanocomposites. Montmorillonite as layered silicate and silica, as spherical nanoparticle, were applied. Microstructure of samples was studied by means of Fourier transform infrared spectroscopy (FTIR), X-ray diffraction (XRD) and transmission electron microscopy (TEM). Thermal properties of samples were examined using differential scanning calometry (DSC) and thermogravimetric analysis (TGA). Hence, shape effect of nanoparticles was studied.

\section{Experimental}

\subsection{Materials}

Hexamethylenediamine (HDMA) and adipoyl chloride (AdCl, 99\% purity) as monomers were purchased from 
Table 1. Some properties of nanoparticles.

\begin{tabular}{lc}
\hline Silica & \\
BET surface & $175-225 \mathrm{~m}^{2} \mathrm{~g}^{-1}$ \\
Tamped density & $40 \mathrm{~g} \mathrm{l}^{-1}$ \\
Diameter & $25-40 \mathrm{~nm}$ \\
NaMMT & \\
Density & $2-2.7 \mathrm{~g} \mathrm{ml}^{-1}$ \\
\hline
\end{tabular}

Acros Organics and Sigma-Aldrich companies. Xylene, as organic solvent, was supplied by Fisher Scientific. NaMMT and pyrogenic silica, grade N20st, were prepared from Southern clay and Wacker Co., respectively. Table 1 lists some main properties of nanoparticles. For by-product removal, pure nonhydrated calcium carbonate $\left(\mathrm{CaCO}_{3}\right)$ was bought from Acros Organics. Methanol, for separation, was supplied by Merck Co. All materials were used as supplied.

\subsection{Nanocomposite preparation}

A quantity of $4.03 \mathrm{~g}$ of HDMA was dissolved in $264 \mathrm{ml}$ of distilled water inside the reactor and mixed $(500 \mathrm{rpm})$ for 15 $\mathrm{s}$ to get a uniform solution. Then, $4.64 \mathrm{~g}$ of $\mathrm{CaCO}_{3}$ was added and stirred for $10 \mathrm{~min}$ at $500 \mathrm{rpm}$. A cloudy suspension was achieved. In a separate container, $5.9 \mathrm{ml}$ of $\mathrm{AdCl}$ was added to $275 \mathrm{ml}$ of xylene with required amount of nanoparticles were mixed to produce organic phase. Suspension was stirred in a reactor for $10 \mathrm{~min}$ at $1000 \mathrm{rpm}$ by a mechanical mixer. Subsequently, the suspension was ultra-sounded by a Misonix Sonicator 3000 for $60 \mathrm{~min}$. Finally, organic phase was added to the suspension after $30 \mathrm{~s}$, while mixture was stirred. The reactive mixture was stirred for $2 \mathrm{~min}$ at $1500 \mathrm{rpm}$. Polycondensation and nanoparticles dispersion occurred simultaneously. The precipitated polymer was collected on filter paper in a Buchner funnel and washed with 11 of $30 \mathrm{vol} \%$ methanol in water and 11 hot water $\left(80^{\circ} \mathrm{C}\right)$. It was vacuum dried at $100^{\circ} \mathrm{C}$ until the excess liquid was removed. The collected polymer was further washed with boiling methanol for $12 \mathrm{~h}$ in a Soxhlet extraction apparatus. Then, mixture was filtered to get the polymer. Finally, the polymer was dried at

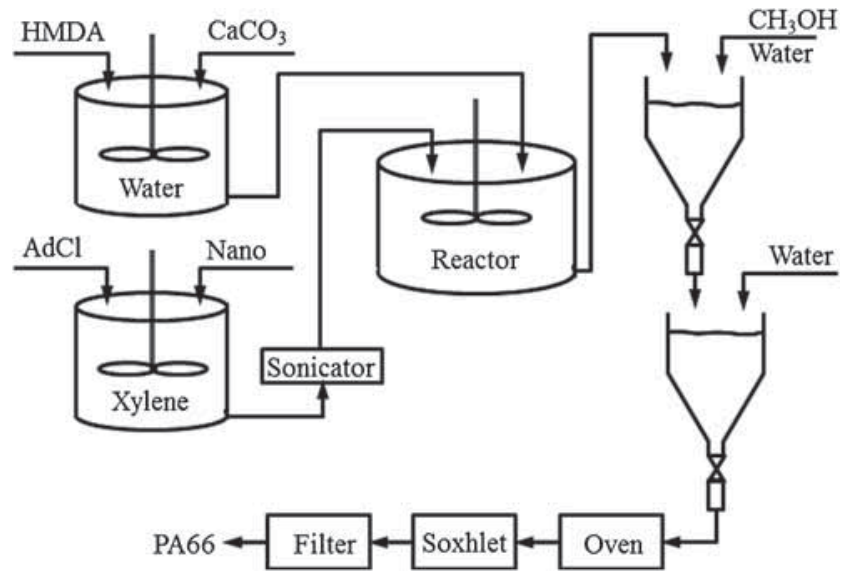

Figure 1. Schematic of the process.
Table 2. List of samples.

\begin{tabular}{lccc}
\hline Sample & Code & Filler & Filler amount (\%) \\
\hline 1 & PA66 & - & - \\
2 & PA66/silica2 & Silica & 2 \\
3 & PA66/silica4 & Silica & 4 \\
4 & PA66/NaMMT2 & NaMMT & 2 \\
5 & PA66/NaMMT4 & NaMMT & 4 \\
\hline
\end{tabular}

$100^{\circ} \mathrm{C}$ overnight. Figure 1 shows schematic of the process. Table 2 shows the list of prepared samples.

\subsection{Characterization}

FTIR, model Nexus 670 from Nicolet Co., was used to study the structure of samples. FTIR spectroscopy was recorded using KBreplete. Dispersion of nanoparticles in samples was studied by small and wide-angle X-ray diffraction (XRD), model NEXUS 670, Nikolet and TEM, model EM10C, Zeiss, Germany. Samples crystallinity was examined using DSC, model DSC1METTLER TOLEDO, Switzerland.

\section{Results and discussion}

\subsection{Characterization}

Figure 2 shows FTIR of the samples. In PA66 spectrum, the peak at $3304 \mathrm{~cm}^{-1}$ belong to $\mathrm{N}-\mathrm{H}$ stretching bond. The peak at $3079 \mathrm{~cm}^{-1}$ indicates $\mathrm{C}-\mathrm{H}$ stretching bond. $\mathrm{C}-\mathrm{N}$ stretching bond gives three peaks at 1640, 1539 and $1269 \mathrm{~cm}^{-1}$. Hence, PA66 is synthesized. In silica spectrum, the peak at $1097 \mathrm{~cm}^{-1}$ represents $\mathrm{Si}-\mathrm{O}-\mathrm{Si}$ bonds. The peak around $3400 \mathrm{~cm}^{-1}$ shows $\mathrm{Si}-\mathrm{OH}$ bonds. In NaMMT spectrum, the peak $1000-1200 \mathrm{~cm}^{-1}$ shows $\mathrm{Si}-\mathrm{O}$ bonds. The peak around $3400 \mathrm{~cm}^{-1}$ represents $\mathrm{Si}-\mathrm{OH}$ bonds. Comparison of spectrum of NaMMT with PA66/NaMMT samples shows that there are some peaks corresponding to NaMMT. It is same for PA66/silica sample. Hence, it is observed that nanoparticles are incorporated in nanocomposites.

Figure 3 shows results of small angle XRD. In PA66 sample, no peak is observed. However, in XRD of NaMMT, there is a peak around $2 \theta=8.2^{\circ}$. Using the Braggs equation, the basal spacing of NaMMT is equal to $12.51 \AA$. In PA66/NaMMT, there are two peaks. One strong peak around $2 \theta=6.8^{\circ}(d=15.08 \AA)$ shows increase in NaMMT layer interval. Hence, polymer is entered into the interlayer spaces and exfoliated structure was formed. Another peak in $2 \theta=11.8^{\circ}(d=8.7 \AA)$, showing decrease of some layer interval, indicating the intercalated structure formation, however, its intensity is small. So it could be concluded that a hybrid exfoliated-intercalated structure has been formed. Silica shows a wide peak in the range of $2 \theta=18-23^{\circ}$ [32] corresponding to $d=5.72-4.49 \AA$. In PA66/silica, a wide peak $2 \theta=11-14^{\circ}$ corresponding to $d=9.33-7.34 \AA$ shows the presence of silica particles in the sample and dispersion of 


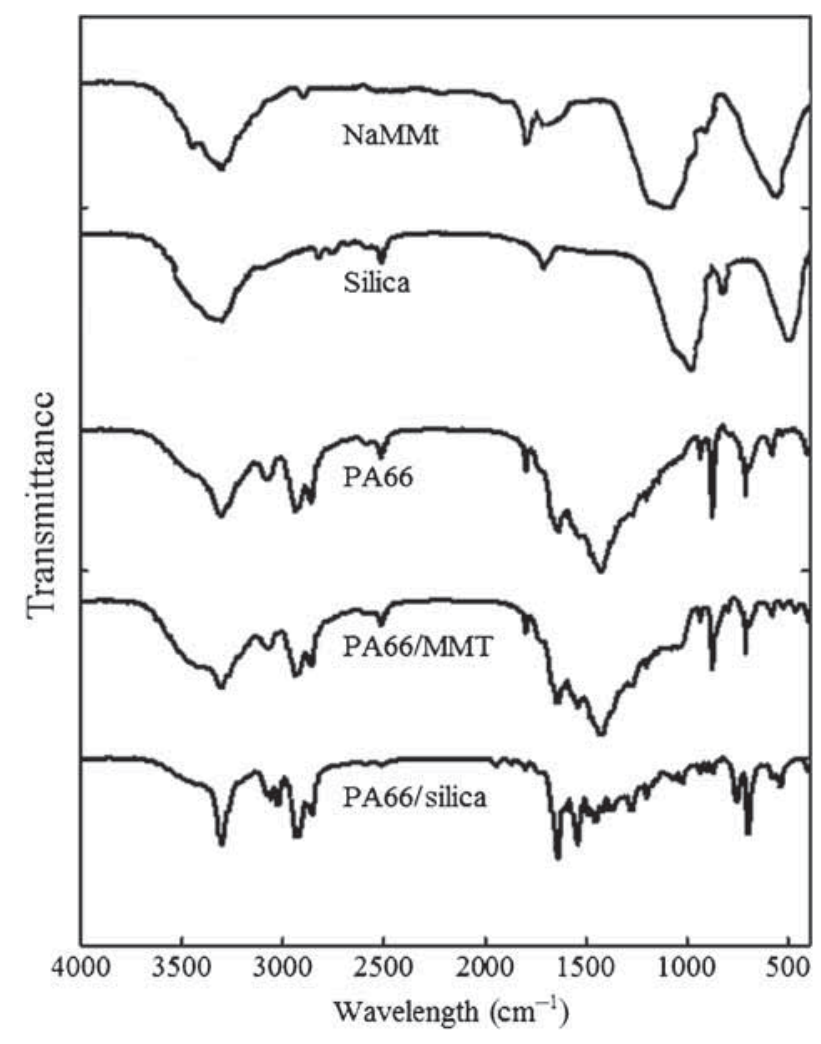

Figure 2. FTIR spectra of samples.

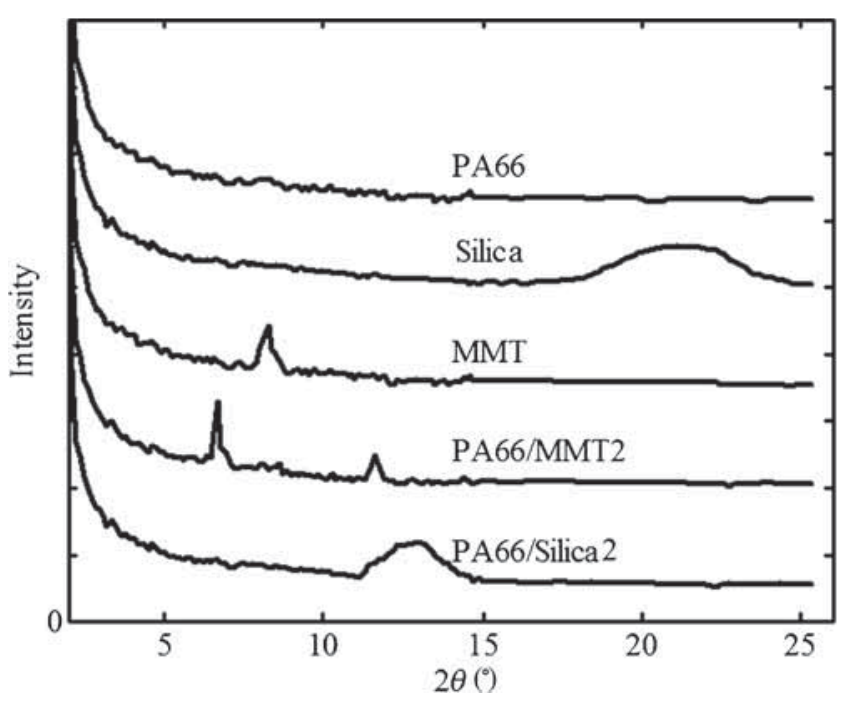

Figure 3. XRD curves of samples.

silica in polymer. Therefore, it is observed that there is a partial exfoliation of nanolayers. Considering the results of XRD diagrams, it could be seen that when NaMMT dispersed in PA66, the basal spacing of nanofiller is increasing about $2.57 \AA$ (15.08-12.51), whereas dispersing of silica in PA66, at the same condition, resulting a displacement about $3.61 \AA$, so it is obvious that displacement of silica nanoparticles are more than one for NaMMT nanoparticles. Hence, it is concluded that silica gives better dispersion than MMT in preparation of PA66 nanocomposites via interfacial polycondensation.

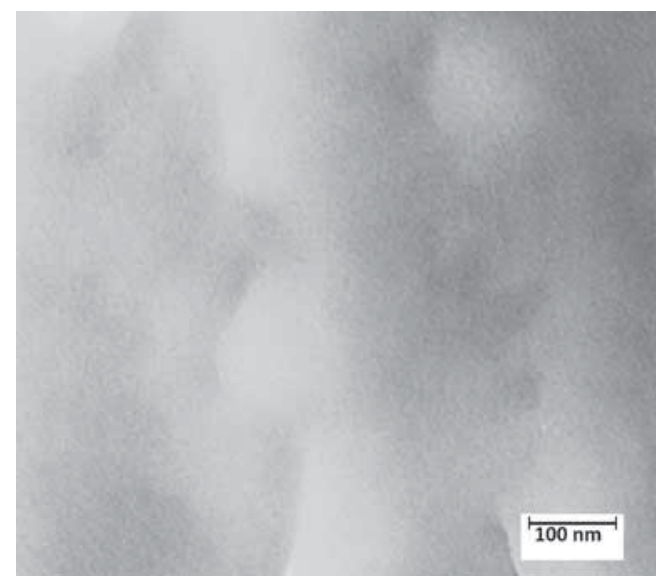

Figure 4. TEM of sample PA66/silica2.

Figure 4 shows TEM of sample PA66/silica. Dark parts represent mineral nanoparticles and light parts show polymer. Therefore, it is concluded that exfoliation is occurred. DSC thermographs of cooling and heating of samples are shown in figure 5. Related data are reported in table 3 . It could be seen that $T_{\mathrm{g}}$ of nanocomposites are increased. More nanoparticles, more $T_{\mathrm{g}}$ increase was measured. Nanoparticles decrease polymer chains mobility; hence, $T_{\mathrm{g}}$ increase is expectable.

Degree of crystallinity $\left(\chi_{c}\right)$ was calculated by the following equation:

$$
\chi_{\mathrm{c}}=\left(\frac{\Delta H_{\mathrm{m}}}{\Delta H_{\mathrm{m} 0}(1-\phi)}\right) \times 100,
$$

where $\Delta H_{\mathrm{m}}$ is measured heat of fusion, $\Delta H_{\mathrm{m} 0}$ the heat of fusion of $100 \%$ crystalline polymer, which is $188 \mathrm{~J} \mathrm{~g}^{-1}$ [33] and $\phi$ the clay content in polymer. It is observed that degree of crystallinity does not change significantly by nanoparticles. In figure 5 , it is seen that crystallization temperature $\left(T_{\mathrm{c}}\right)$ shifts to higher temperatures with nanoparticles and width of peaks $\left(\Delta T_{\mathrm{c}}\right)$ decreases. PA66/silica has the maximum $T_{\mathrm{c}}$ value $\left(230.68^{\circ} \mathrm{C}\right)$. Increase in $T_{\mathrm{c}}$ suggests that interaction between nanoparticles and matrix occurs [34]. It could be attributed to strong interactions among PA66 chains and hydroxyl groups in silica [34]. According to table $3, \Delta T_{\mathrm{c}}$ of nanocomposites were smaller than the $\Delta T_{\mathrm{c}}$ of PA66. $\Delta T_{\mathrm{c}}$ is related to overall crystallization rate. Heat of fusion, $\Delta H_{\mathrm{c}}$ represents extent of crystallinity; therefore, the term $\Delta H_{\mathrm{c}}$ is the index of crystallization rate. As nanoparticles increase, crystallization rate increases. These results imply that crystallization of PA66 is accelerated by incorporating nanoparticle. Another important term is super cooling degree, defined as $\Delta T=T_{\mathrm{m}}-T_{\mathrm{c}} . \Delta T$ conceptually shows overall crystallization rate. Hence, less super cooling degree means higher overall crystallization rate. In table $3, \Delta T$ decrease could be attributed to nucleation mechanism [35]. In heating run, melting temperature $\left(T_{\mathrm{m}}\right)$ of nanocomposites is higher than $T_{\mathrm{m}}$ of PA66. The higher $T_{\mathrm{m}}$ was attributed to melting of more perfect crystals [34] formed as a result of the nucleation effect of nanoparticles during cooling run. PA66/silica has less $\Delta T_{\mathrm{m}}$. It is concluded that distribution of crystallites in 

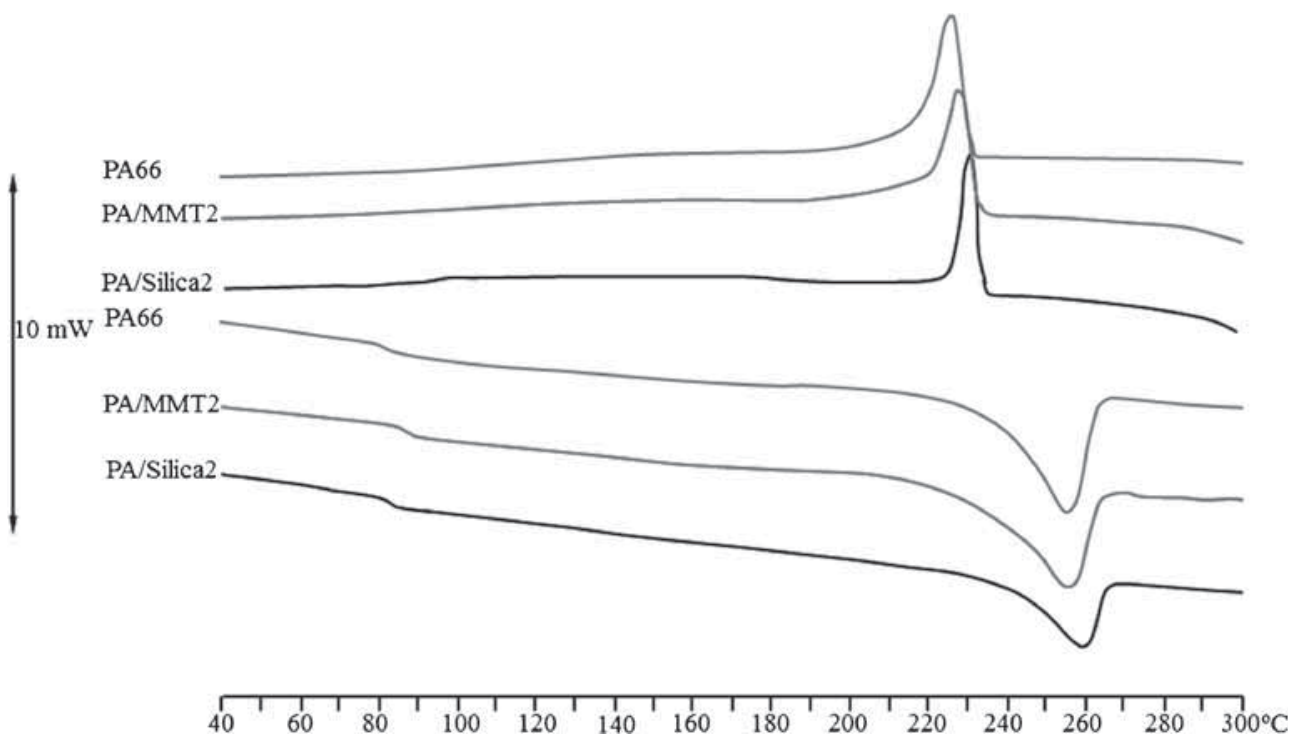

Figure 5. Heating and cooling thermograms.

Table 3. DSC test data.

\begin{tabular}{lccccccccc}
\hline Sample & $T_{\mathrm{g}}\left({ }^{\circ} \mathrm{C}\right)$ & $T_{\mathrm{c}}\left({ }^{\circ} \mathrm{C}\right)$ & $\Delta T_{\mathrm{c}}\left({ }^{\circ} \mathrm{C}\right)$ & $\Delta H_{\mathrm{c}}\left(\mathrm{J} \mathrm{g}^{-1}\right)$ & $\Delta T\left({ }^{\circ} \mathrm{C}\right)$ & $\chi_{\mathrm{c}}(\%)$ & $T_{\mathrm{m}}\left({ }^{\circ} \mathrm{C}\right)$ & $\Delta H_{\mathrm{m}}(\mathrm{J} \mathrm{g}-1)$ & $\Delta T_{\mathrm{m}}\left({ }^{\circ} \mathrm{C}\right)$ \\
\hline PA66 & 81.9 & 225.35 & 13.81 & 35.35 & 29.26 & 19.64 & 254.61 & 36.93 \\
PA66/NaMMT2 & 87.8 & 227.32 & 13.37 & 48.44 & 27.73 & 18.67 & 255.05 & 35.11 \\
PA66/silica2 & 83.6 & 230.68 & 8.16 & 43.47 & 25.2 & 19.10 & 258.88 & 35.92 & 24.62 \\
PA66/NaMMT4 & 89.7 & 229.27 & 11.89 & 51.67 & 24.53 & 19.02 & 255.74 & 35.76 \\
PA66/silica4 & 86.9 & 233.45 & 5.24 & 47.92 & 22.76 & 19.47 & 259.12 & 36.60 \\
\hline
\end{tabular}

nanocomposites was narrower than that of PA66. Decreasing overall crystallization rate and constant degree of crystallization and increasing the number of nucleus with clay content suggest that heterogeneous nucleation occurs in nanocomposites that leads to increase in the number of crystals, but in smaller size. In comparison with melt mixing process [35], nanocomposite with more nanoparticles has smaller $\Delta T_{\mathrm{m}}$ reflecting narrower crystal size distribution.

Nonisothermal crystallization kinetic can be directly analysed by the Avrami equation:

$$
X_{\mathrm{T}}=1-\exp \left(-Z_{\mathrm{t}} \cdot t^{n}\right) .
$$

Relative crystallinity as a function of temperatures $\left(X_{\mathrm{T}}\right)$ is defined as:

$$
X_{\mathrm{T}}=\frac{\int_{T(0)}^{T(t)}\left(\mathrm{d} H_{\mathrm{c}} / \mathrm{d} T\right) \mathrm{d} T}{\int_{T(0)}^{T(\infty)}\left(\mathrm{d} H_{\mathrm{c}} / \mathrm{d} T\right) \mathrm{d} T},
$$

where $T(0)$ and $T(t)$ are the initial and final temperatures of crystallization and $\mathrm{d} H_{\mathrm{c}} / \mathrm{d} T$ is heat flow. Relative crystallinity could be described as a function of time $(t)$ :

$$
X_{\mathrm{T}}=\frac{\int_{0}^{t}\left(\mathrm{~d} H_{\mathrm{c}} / \mathrm{d} T\right) \mathrm{d} T}{\int_{0}^{\infty}\left(\mathrm{d} H_{\mathrm{c}} / \mathrm{d} T\right) \mathrm{d} T} .
$$

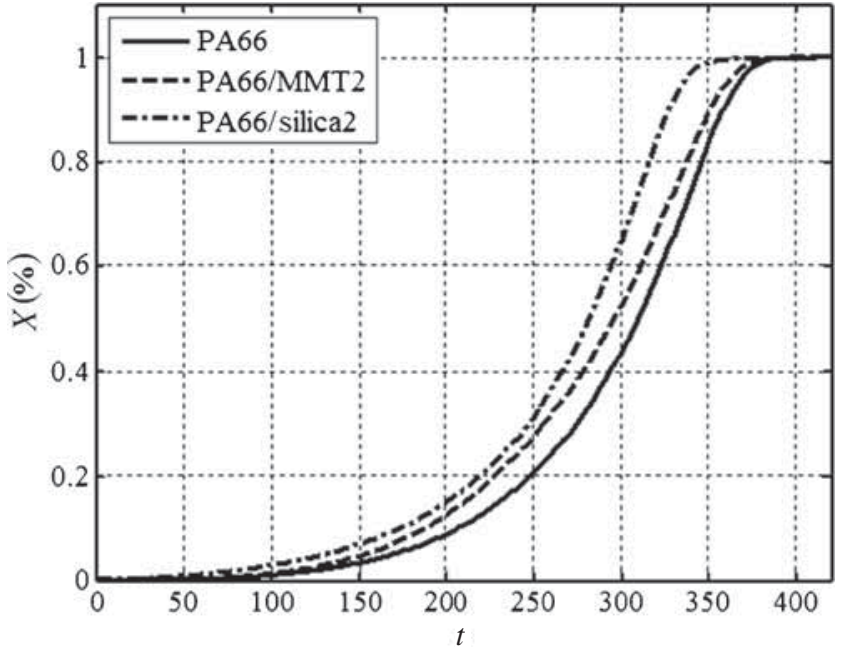

Figure 6. Crystallinity\% of samples vs. time.

Figure 6 illustrates relative crystallinity $\left(X_{\mathrm{t}}\right)$ of samples $v s$. time. All curves show a sigmoid trend and rate of crystallization increases with nanoparticles, as seen in table 3 . It is observed that crystallinity rate is increased by adding nanoparticles. In the case of silica, crystallization is faster. 


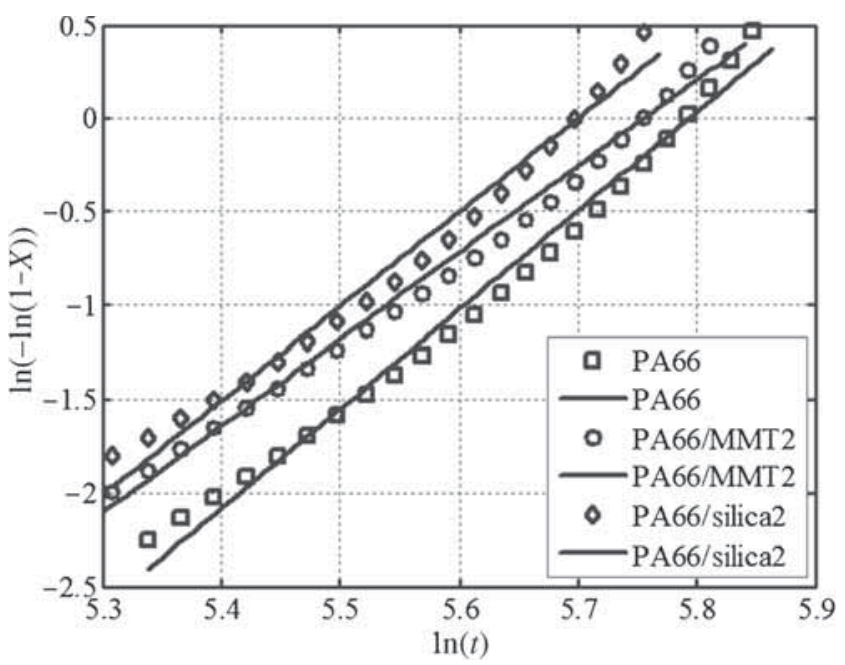

Figure 7. Double logarithmic equation of Avrami model.

Table 4. Kinetic parameters based on the Avrami equation.

\begin{tabular}{lcc}
\hline Sample & $Z_{\mathrm{t}}$ & $n$ \\
\hline PA66 & $4.9466 \times 10^{-14}$ & 5.29 \\
PA66/NaMMT2 & $2.8392 \times 10^{-12}$ & 4.62 \\
PA66/silica2 & $3.6230 \times 10^{-13}$ & 5.02 \\
PA66/NaMMT4 & $3.7239 \times 10^{-12}$ & 4.85 \\
PA66/silica4 & $5.3402 \times 10^{-13}$ & 5.13 \\
\hline
\end{tabular}

Hence, silica could have more nucleation effects. To calculate Avrami parameters ( $n$ and $Z_{\mathrm{t}}$ ), a double-logarithmic form was used:

$$
\ln \left[-\ln \left(1-X_{\mathrm{t}}\right)\right]=\ln Z_{\mathrm{t}}+n \ln (t),
$$

where $Z_{\mathrm{t}}$ is crystallization rate constant involving both nucleation and growth rate parameters and Avrami exponent, $n$ is a constant depends on type of nucleation and growth processes. Figure 7 shows $\ln \left[-\ln \left(1-X_{\mathrm{t}}\right)\right] v s . \ln (t)$. Calculated $n$ and $Z_{\mathrm{t}}$ values are given in table $4 . n$ values are in the range of 4.62-5.29. For PA66, $n=5.29$. Hence, it is concluded that crystal growth is spherulitic and nucleation mechanism is homogeneous [36]. By adding nanoparticles, $n$ decreases for nanocomposites that are indication of heterogeneous nucleation in the presence of nanoparticle [35]. $Z_{\mathrm{t}}$ increases with nanoparticles, and PA66/silica1 has the highest crystallization rate. The curve of PA66 exhibits a nonlinear behaviour indicating a secondary crystallization process [37]. Based on the results; it is observed that silica could give better thermal properties to the PA66 nanocoposites.

\section{Conclusions}

PA66 homopolymer and its nanocomposites with montmorillonite and nanosilica were prepared via in situ interfacial polymerization. FTIR results show that the synthesized samples are PA66. Samples structure was studied using XRD and TEM. XRD and TEM indicate that exfoliation structure is formed. Thermal properties were studied using DSC. It was observed that $T_{\mathrm{g}}$ was increased. Crystallinity changed to heterogeneous nucleation. XRD and TEM results show the partially exfoliated structure in PA66/nanosilica nanocomposite. On the other hand, PA66/NaMMT nanocomposites seem to have hybrid intercalated-exfoliated structure because of two peaks showing in the XRD curve. So, it could be concluded that the shape of nanoparticle affects the final nanocomposite structure as well as crystallization behaviour of samples.

\section{Acknowledgements}

We would like to acknowledge Dr Mir Mohammad Sadeghi, Department of Polymer Engineering and Color Technology, Amirkabir University of Technology, for her kind help and assistance.

\section{References}

[1] Carothers W H 1937 Linear condensation polymers US Patent 2071250A

[2] Kohan M I 1995 Nylon plastics handbook (Munich: Hanser Gardner Publishers)

[3] Morgan P W 1965 Condensation polymers: by interfacial and solution methods (New York: Interscience Publishers)

[4] Carraher C E 1966 Seymour/Carraher's polymer chemistry: an introduction 4th edn (New York: Marcel Dekker)

[5] Fathizadeh M, Aroujalian A and Raisi A 2012 Desalination 28432

[6] Matthews T D, Yan H, Cahill D G, Coronell O and Marinas B J 2013 J. Membrane Sci. 42971

[7] Lee J, Hill A and Kentish S 2013 Sep. Purif. Technol. 104276

[8] Hermans S, Mariën H, Dom E, Bernstein R and Vankelecom I F J 2014 J. Membrane Sci. 451148

[9] Liu X and Wu Q 2002 Macromol. Mater. Eng. 287180

[10] Liu X, Wu Q and Berglund L A 2002 Polymer 434967

[11] Zhu C S, Kang X, He S Q, Wang L Y and Lu L Y 2002 Chin. J. Polym. Sci. 20551

[12] Liu X and Wu Q 2002 Macromol. Mater. Eng. 287180

[13] Mehrabzadeh M and Kamal M R 2004 Polym. Eng. Sci. 44 1152

[14] Hedicke K, Wittich H, Mehler C, Gruber F and Altstadt V 2006 Compos. Sci. Technol. 66571

[15] Yang Q Q, Guo Z X and Yu J 2008 Chin. J. Polym. Sci. 26 689

[16] Araujo E M, Araujo K D, Paz R A, Gouveia T R, Barbosa R and Ito E N 2009 J. Nanomater. 20091155

[17] Bescoa S, Lorenzettia A, Rosoa M and Modestia M 2011 Polym. Adv. Technol. 221518

[18] Zou H, Wu S and Shen J 2008 Chem. Rev. 1083893

[19] Sengupta R, Bandyopadhyaya A, Sabharwal S, Chakia T K and Bhowmick A K 2005 Polymer 463343 
[20] Lu H, Xu X, Li X and Zhang Z 2006 Bull. Mater. Sci. 29485

[21] Xu X, Li B, Lu H, Zhang Z and Wang H 2007 Appl. Surf. Sci. 2541456

[22] Botelho E C, Scherbakoff N and Rezende M C 2002 Polym. Int. 511261

[23] Zhang A, Ma R, Xie Y, Xu B, Xia S and Gao N 2012 Desalin. Water Treat. 37238

[24] Kang M, Myung S J and Jin H J 2006 Polymer 473961

[25] Haggenmueller R, Du F, Fischer J E and Winey K I 2006 Polymer 472381

[26] Tarameshlou M, Jafari S H, Khonakdar H A, FarmahiniFarahani M and Ahmadian S 2007 Polym. Compos. 28733

[27] Song L, Hu Y, He Q and You F 2008 Colloid. Polym. Sci. 286 721

[28] Kalkan Z S and Goettler L A 2009 Polym. Eng. Sci. 491491
[29] Kalkan Z S and Goettler L A 2009 Polym. Eng. Sci. 491825

[30] Kalkan Z S and Goettler L A 2012 Polym. Eng. Sci. 522410

[31] Kherroub D E, Belbachir M and Lamouri 2015 Bull. Mater. Sci. 4857

[32] Shirali H, Rafizadeh M and Taromi F A 2014 J. Compos. Mater. 48301

[33] Du Pont Nylon 66 datasheet 2003 8528. Nylon 6.6, 21/3/03

[34] Broza G, Kwiatkowska M, Roslaniec Z and Schulte K 2005 Polymer 465860

[35] Wan C, Bao X, Zhao F, Kandasubramanian B and Duggan M P 2008 J. Appl. Polym. Sci. 110550

[36] Wu D, Zhou C, Fan X, Mao D and Bian Z 2006 J. Appl. Sci. 993256

[37] Hwang S Y, Khaydarov A A, Park J Y, Yoo E S and Im S S 2011 Macromol. Res. 19699 